\title{
SOODVISNOSTI REGIONALNEGA IN URBANISTI- ČNEGA PLANIRANJA V REGIONALNEM RAZVOJU SLOVENIJE
}

\author{
Vladimir Braco Mušič \\ Gregorčičeva ulica I3, SI-I000Ljubljana
}

Izvirni znanstveni članek

COBISS 1.01

\section{Izvleček}

Pokrajšem kritičnemuvodnem razmišljanju o soodvisnostihmed regionalnimin urbanističnim planiranjem v splošni teoriji in v slovenski praksi regionalnega in urbanega razvoja, se prispevek osredotoča na vlogo in pomen slovenskega koncepta policentričnega prostorskega razvoja in na problematiko (bolj ali manj načrtnega) razvoja prometne infrastrukture. Pri tem sta najpomembnejša poudarka na vlogi sedanjega in bodočega sistema avtocest in hitrih cest ter na večji vlogi javnega potniškega prometa.

Ključne besede: regionalni in urbani razvoj, policentrični razvoj, avtocestni sistem, prostorski razvoj, Slovenija.

\section{INTERDEPENDENCE OF REGIONAL AND URBAN PLANNING IN THE REGIONAL DEVELOPMENT OF SLOVENIA}

\begin{abstract}
The article focuses on the significance of Slovene's concept of polycentric spatial development, and on the problems (more or less planned) development of transport infrastructure, after the critical introduction of interdependence of regional and urban planning in general theory and Slovene's practice of regional and urban development. Within this context the emphasis is on existing and future system of motorways and greater role of public transport.
\end{abstract}

Key words: regional and urban development, polycentric development, motorway system, spatial development, Slovenia 


\section{UVOD}

Ne glede na dejstvo, da so urbanizem in urejanje širšega prostora poznale že prazgodovinske civilizacije, si bom dovolil trditev, da sta za naše dandanašnje retrospekcije bolj relevantna urbanistično in regionalno planiranje kot otroka 19. in 20. stoletja. Taka trditev je mogoča tudi zato, ker imamo od 1961., oz. od 1969. tudi v slovenskem prevodu, monumentalno delo Lewisa Mumforda Mesto v zgodovini ${ }^{l}$ in od 1998. prav tako monumentalno delo Petra Halla Cities in Civilization ${ }^{2}$. V teh delih so mesta, v svojem širšem vplivnem (funkcionalnem) prostoru in v svojem širšem družbenem kontekstu, predstavljena in definitivno (!) ovrednotena kot žarišča kulture, inovacije in urbanega reda. Idejne osnove razsvetljenstva in izum parnega stroja ter drugih tehnikalij kot energetske in mehansko-tehnološke osnove proizvodnje dobrin in prometa so vplivale na sproženje vrtoglavo hitre rasti mest in vsega drugega kar še danes označujemo s sintagmami industrijska revolucija in proces urbanizacije. Hkrati pa je značilno, da imamo v naši sodobni retrogardnosti (in historiografskem revizionizmu) opraviti s pravcato amnezijo na področju razumevanja soodvisnosti industrijske (in urbane) revolucije, vzrokov in posledic razvoja kapitalizma in socializma, ter implicitnih povezav delavskega gibanja in prostorskega ter urbanističnega planiranja. Naj nam bodo lekcije Mumforda, Halla in stotin drugih avtorjev, ki sva jih velikokrat citirala Vrišer in jaz in mnogi drugi slovenski prostorski planerji in urbanisti, $v$ trajno opozorilo.

Naš današnji slavljenec, akademik Igor Vrišer je na trdnih temeljih, ki so jih postavili Rus, Melik, Ilešič in drugi zgradil pomemben del stavbe sodobne slovenske geografske vede kot nujno potrebne osnove za smotrno urejanje prostora. Upam, da sem z mislimi iz prvega odstavka nakazal družbene in prostorske razsežnosti, na katere je tudi on vztrajno opozarjal, vendar brez velikih besed, ki sem jih jaz namenoma uporabil, glede na pomen njegovega življenskega prispevka in glede na usihanje učinkovite upravne in politične skrbi za naš prostor v naših aktualnih družbenih razmerah.

\section{SOODVISNOST FIZIČNIH IN DRUGIH MERIL}

V Angliji (kot zibelki industrializacije) in na Škotskem, kjer najdemo tudi prvo prostorsko zakonodajo (1909), sta bila merilo mesta in merilo (ter vsebina) širšega vplivnega območja oz. regije, obravnavana skupaj že zelo zgodaj. Ob priliki, kakršna je današnja naj navedem nekaj imen, ki so prehitro izginila iz strokovne literature. Ebenezer Howard (1850-1928) je svojo utopijo "vrtnega mesta « definiral na ravni »idealne« mestne enote in na ravni širšega prostora, ki vključuje tudi agrarno krajino in kapitalno prometno infrastrukturo ${ }^{3}$; Patrick Geddes (1854-1932), biolog, sociolog in planer je bil prvi, ki je razumel soodvisnost mesta

\footnotetext{
${ }^{1}$ I. in II. knjiga, DZS Ljubljana

2 Phoenix London

${ }^{3}$ To-morrow: a Peaceful path to real reform, London 1898; v drugi rev. izdaji: Garden cities of tomorrow, London 1902
} 
in regije kot temeljne geografske in historične strukture, ki tvori kompleksno interakcijo med krajem, delom in ljudmi (Place - Work - Folk), z upoštevanjem izobraževalnih, estetskih in političnih dejavnosti' ${ }^{4}$ P Patrick Abercrombie (1879-1957), ki je bil tako, kot že omenjeni Mumford, pod močnim Geddesovim vplivom, je že 1933. objavil knjigo Town and Country Planning. V zvezi z Geddesom in Abercrombiejem je treba omeniti tudi začetek poglobljene interdisciplinarne analize prostorskih struktur, kot podlage za operativno planiranje, (Survey Before Plan).

Pri nas je temeljno znanstveno in strokovno delo Vrišerjevo Regionalno planiranje6, ki vsebuje tudi še vedno aktualna razmišljanja o relativizaciji učinkov širšega planiranja in o njihovi odvisnosti od nacionalne razvojne politike. Danes bi seveda dodali še vpliv tržnih odnosov v gospodarstvu in (celo) na drugih področjih družbe. Začetki pa segajo dlje nazaj. Naj tu navedem znamenito VI. Posvetovanje urbanistov Jugoslavije, ki se je vršilo leta 1957 $\mathrm{v}$ Aranđelovcu in referat, ki ga je tam podal pok. Marjan Tepina. Še starejši pa je prispevek Edvarda Ravnikarja na I. posvetovanju arhitektov FLRJ v Dubrovniku, leta 1950. Ravnikarjev referat je prva eksplicitna predstavitev decentraliziranega (policentričnega) prostorskega razvoja mest ${ }^{7}$. Svoj zagovor upoštevanja regionalnih razsežnosti urbanizma in izgradnje je Ravnikar opredelil takole:

" ... Odstotek mestnega prebivalstva je res nizek v primeri s starimi industrijskimi deželami, toda vedeti moramo, da v Sloveniji ne moremo govoriti o mestu in deželi kot o dveh nasprotujočih si principih v taki meri, kot npr. na jugu. Bolje je, da dosledno govorimo kmečkem in nekmečkem, kot pa o mestnem in kmečkem prebivalstvu ali naselju. Če govorimo o prenaseljenosti, ne govorimo o absolutni prenaseljenosti, ker bi to bil nesmisel, ampak o agrarni prenaseljenosti. ... Ali ima smisel, da se v času, ko se ves strokovni svet bavi z decentralizacijo, ravno mi urbaniziramo, ko je razporeditev prebivalstva $v$ LR Sloveniji z ozirom na dobro povezanost in lepoto predelov tako ugodna za enakomerno porazdelitev ljudi? ..."

Razmislek, ki ga je avtor predlagal, je zajel vprašanja prometne dostopnosti, splošne značilnosti razvitih držav v primerjavi s kolonijami in načela decentralizacije. Dodana pa je bila tudi primerjalna kalkulacija.

Policentrizem je pozneje postal v Sloveniji kuranten politični koncept, ki je žal vodil tudi v neracionalno drobitev razvojnih prizadevanj po občinah in celo po krajevnih skupnostih. Po drugi strani pa moramo danes, po 55 letih, ugotoviti, da se je v našem prostoru in zlasti v prostoru večjih mest ali že obstoječih somestij, izrazil nov, »regionalni« fenomen mesta, ki kohezijo svojih sestavin črpa iz prometne dostopnosti ter iz vrtoglavega razvoja informacijsko komunikacijske tehnologije. Naj dodam, da je pomen »obmestja« močno poudaril tudi Igor Vrišer v svoji knjižici Razvoj prebivalstva na območju Ljubljane ${ }^{8}$.

$\mathrm{Na}$ koncu 50-ih let je prišlo v Sloveniji do pomembnih poskusov konsolidacije urbanistične in regionalno-prostorske službe. Ustanovljeni so bili novi urbanistični zavodi

\footnotetext{
${ }^{4}$ Cities in Evolution, London 1915

${ }^{5}$ Oxford University Press, London (do 1952. 6 izdaj)

${ }^{6}$ MK, Ljubljana 1978

${ }^{7}$ Problemi arhitekture in urbanizma LRS, ured. France Ivanšek; izd. Arh. sekcija inženirjev in tehnikov LR Slovenije, Ljubljana 1950.
} 
v vseh večjih mestih in z delom je pričel Urbanistični inštitut SRS. V ospredje je stopilo tudi vprašanje širšega, regionalnega planiranja. Naj povzamem dva odlomka iz takratnega pisanja Marjana Mušiča:

»Praksa nas vsepovsod sili, da rešujemo često velike naloge, ki so sicer krajevno nadvse pogojene, brez zadostnega vpogleda $v$ širše relacije, kakor jih more edinole pravilno odrediti regionalni urbanistični program in na njem osnovani regionalni in urbanistični načrt. Ne torej nizati podrobnosti, detajlov, kakor jih predstavljajo nešteti aktualni mikrorajoni, često brez ozira na celoto, marveč moramo čimprej pristopiti k oblikovanju mikrorajonov na osnovi dobro proučenih in preverjenih okvirnih programov regionov in makrorajonov. Da pa je možno to doseči, je potrebno temeljito reorganizirati celotno urbanistično službo in jo usposobiti $v$ občutjiv organ teoretske in praktične dejavnosti. Le na ta način bo onemogočena stihija, bo onemogočeno nekvalitetno ali ne dovolj kvalitetno strokovno delo in bodo šle v pozabo tudi različne nepravilnosti samolastnih ukrepov, ki se ponekod pojavljajo in slabe kvalitetni vzpon ter jemljejo voljo prizadevnim strokovnjakom. ... Omenil sem bil že, da bi bilo nujno potrebno pristopiti k regionalnemu načrtovanju. K temu nas sili skrb za racionalno in estetsko oblikovanje celotnih, v sevbi zaključenih regij, vključujoč temeljito preobrazbo glede uporabe obdelovalnih, zazidalnih in zaščitenih predelov. Vsepovsod nastajajo nova proizvodna središča, ob njih pa aglomeracije naselij, ki so nanje organsko vezane. Tudi naše obdelovalne površine so pred velikimi, daljnosežnimi posegi, ki bodo bistveno preoblikovali njihov dotlej značilni izgled. Izraz naše pokrajine, ki ima še vedno vse značilnosti tradicionalnih, historičnih kultur, se bo bistveno preobrazil z novimi elementi, ki jih narekujeta nova namembnost in gospodarstvenost. ${ }^{9}$

Pisec zgornjih vrstic je v nadaljevanju konkretiziral svoja opozorila s primeri načrtovanih velikih živinorejskih farm, 200 po številu in v standardizirani velikosti $\gg 400$ krav na 400 hektarjih«. Akcijo naj bi začeli na Sorškem polju in nadaljevali višje na Gorenjskem, tudi v vidnem polju Prešernove Vrbe. In so jo tudi začeli. V zadnjem trenutku je mlada urbanistična stroka uspela korigirati lokacijo hlevov nekje med Žabnico in Bitnjami ter omejiti izsekavanje ravninskih gozdov na levem in desnem bregu reke Save, tudi z opozorili na mikroklimatske in druge okoljske posledice. ${ }^{10}$ Skrb za razvoj in uveljavljanje regionalnega prostorskega planiranja se je končno odrazila s sprejemom ustreznega zakona ${ }^{11}$ in $\mathrm{z}$ ustanovitvijo posebne komisije na ravni takratne slovenske vlade, vendar v praksi ni bilo pričakovanih učinkov. Namesto vztrajnega pripravljanja in izvajanja širših in daljnoročnih prostorskih planov, smo se motovilili od projekta do projekta in od afere do afere po vzorcu, ki ga vidimo še danes.

Razmerja med teorijo in prakso sem, $\mathrm{v} »$ jubilejnih letih« obdelal $\mathrm{v}$ dveh pisnih prispevkih, ki zajemajo tudi tematiko tega prispevka. Ob 40 obletnici začetka dela Urbanističnega inštituta

\footnotetext{
${ }^{8}$ Knjižnica »Kronike«, zv. 2, Ljubljana 1956

${ }^{9}$ Marjan Mušič: Nova pota urbanizma pri nas (Ob občnem zboru slovenskega urbanističnega društva); Naši razgledi, 20. decembra 1959, str. 586-587.

${ }^{10}$ Državna uprava me je takrat imenovala za predsednika Komisije za zaščito Sorškega polja, moj tajnik pa je bil gozdarski inženir Ciglar, eden od podsekretarjev v takratnem ministrstvu za kmetijstvo. Zanimivo je, da je varstveno akcijo sprožil s svojo veliko avtoriteto reteški rojak, znameniti stomatolog (in lovec!), prof. dr. Rant. ${ }^{11}$ Gl. Tudi Milan Naprudnik: Regionalno prostorsko planiranje v Sloveniji - I. del, str. 76-80 v reviji Urbani izziv 15/2, UIRS Ljubljana 2004.
} 
(Socialistične) republike Slovenije sem razpravljal o usodi dveh teoretskih konceptov, ki sta dominirala v strokovnem diskurzu označenega obdobja in sicer »optimalna velikost mest« in »Vzdržnost (ali trajnostnost) mest « ${ }^{12}$ ter širšo pogojenost razmerij med mestom in urbanizmom oz. teorijo in prakso enega in drugega ${ }^{13}$. Tu ne bi želel ponavljati svojih ugotovitev in trditev, ki problematizirajo učinkovitost našega prostorskega planiranja na regionalni in mestni ravni, čeprav je marsikaj aktualno še sedaj ali pa vedno bolj. Te dni se naša Vlada in Državni svet soočata z resnimi posledicami dejstva, da v preteklih letih nismo zmogli uvesti smotrne členitve države na regije in nam zdaj grozijo finančne posledice v okvirih Evropske unije. Krivde za neupoštevanje soodvisnosti regionalnega in urbanističnega planiranja $\mathrm{v}$ regionalnem razvoju Slovenije ali, če hočete, v merilu razvoja celotne Slovenije, prav gotovo ne more prevzemati naša širša stroka in še manj naše ožje stroke, $z$ geografsko na čelu. Za zaplete pri formiranju regij, ki smo jih videli v zadnjih letih mislim, da so krive naše politične stranke in v tem primeru zlasti stranke bivše opozicije oz. sedanje pozicije, ki so se ustrašile potencialne prevlade (o)pozicije $\mathrm{v}$ regijah. V svojem arhivu hranim več besedil, ki sem jih bil pripravil za eno oz. celo za dve od naših političnih strank v zgodnjih 90-ih letih, zavzemajoč se za institucionalizacijo regij, predvsem zaradi boljše artikulacije regionalno razvojnih nalog. Zaman in celo brez vzvratnega vpliva ... Življenje seveda ne čaka na tako ali drugačno ureditev programskega, načrtovalskega in usmerjevalnega dela, temveč zelo hitro odraža prevlado interesov najmočnejših in najspretnejših dejavnikov. Ti interesi pa kot vemo, niso vedno tudi interesi družbe kot celote ali interesi neke lokalne družbene skupnosti, temveč predvsem interesi kapitala in dobička.

$\mathrm{V}$ okvirih ene od zelo delavnih organizacij civilne družbe, kjer sem končno, kot upokojenec pristal, sem že (ali še) v začetku leta 2002, postavil nekaj tez v zvezi z državnim usmerjanjem procesov urbanizacije in regionalega razvoja ${ }^{14}$. Naj mi bo dovoljeno prenesti sem del teh tez in dele besedil, ki uvajajo ali utemeljujejo te teze. Kot je bilo rečeno v opombi pod črto $\left.{ }^{(14}\right)$ navajam iz knjižne publikacije, ki pa verjetno doseže žal le ozek krog zainteresiranih strokovnjakov. Žal to in tako pisanje doseže še manjši krog poslancev DZ in operativnih državnih politikov in uradnikov, čeprav pomembnejše gradivo in zaključke Društva Občanski forum objavlja tudi Državni svet v svoji informativni publikaciji. (Tisti Državni svet, ki bi ga, tudi kot tribuno civilne družbe, nekateri jurišniki nove partitokratske pozicije radi čimprej ukinili!)

\footnotetext{
${ }^{12}$ Vladimir Braco Mušič: From 'Optimum Size for Cities' to 'Sustainability of Cities', str. 50-57 v zborniku 20th Century Urbanisation and Urbanism - Urban Debate on the Eve of the New Millenium; ed. Barbara Černič Mali; Mednarodna konferenca na Bledu 9. - 11. december 1999.

${ }^{13}$ Vladimir Braco Mušič: Mesto in urbanizem med teorijo in prakso, str. 309-331 v Teoriji in praksi 41/1-2, Ljubljana 2004.

${ }^{14}$ Objavljeno v knjigi POLITEA - civilne razsežnosti politike; zal. FDV in Društvo Občanski forum, Ljubljana 2004; gl. Vladimir Braco Mušič: Urbanistični vidiki (izhodišč za razpravo o razvojnih programih Ljubljane /in/ udeležbi občanov pri odločanju), str. 11-16.
} 


\section{NEKAJ DEJAVNIKOV RAZVOJA V PROSTORU IN PROSTORSKEGA RAZVOJA}

Državno usmerjanje procesov urbanizacije in regionalnega razvoja, (ki po nekdanjem, do danes močno izrojenem konceptu policentrizma, praktično ne obstaja več), bo v bodoče podprto z nedavno sprejeto Politiko prostorskega razvoja, z novimi zakoni s področja urejanja prostora in graditve in s prostorskim planom države, ki je bil sprejet pod nazivom strategija. Našteti dokumenti bodo, če bodo obveljali v novi politični konstelaciji in če bodo podprti s potrebnimi podzakonskimi akti, ki bodo še sledili, (a o njihovi vsebini žal še ne vemo veliko!) in (upajmo, da tudi) s konsolidacijo upravnih in strokovnih služb na področju urbanizma, lahko predstavljali učinkovita orodja za zaustavitev in preusmeritev škodljivih trendov razpršenega poseljevanja, oz. »popredmestenja Slovenije«. Mimo disperzne gradnje, zlasti v pasovih vzdolž glavnih prometnih koridorjev pa nekateri podatki in kazalci kažejo na začetke procesa hitrejše rasti (»Velike«) Ljubljane, Obalnega somestja, Novega mesta in še nekaterih urbaniziranih regij Slovenije. V jasnejši polarizaciji glavnih središč urbane koncentracije nasproti tkim. podeželju je verjetno ena od možnosti za boljši položaj naših mest v tekmi z urbanimi centri evropskih držav. Pri tem moramo vsekakor upoštevati tudi boljšo prometno dostopnost in vse večjo vlogo informacijsko-komunikacijske tehnologije $\mathrm{v}$ produktivni interakciji različnih dejavnikov razvoja. Polarizacija o kateri govorimo pa ne sme pomeniti zapostavljanja ali zanemarjanja perifernih, pretežno ruralnih regij in regij ter mest, ki so se nekoč, v procesu prvobitne industrializacije uspešno razvijala in potem opešala že na samem začetku procesa terciarizacije in kvartarizacije gospodarstva, mora pa pomeniti primeren poudarek mestom, kot nosilcem razvoja. Z vidika mesta Ljubljane je treba reči, da usmerjanje razvoja glavnega mesta države ne more biti odvisno zgolj od organov mestne samouprave, temveč sodi kot posebno poglavje v vse državne razvojne dokumente. Menim, da je odsotnost ali invalidnost vloge države pri usmerjanju procesov urbanizacije, najbolj vidna pri naslednjih programskih sklopih:

- zemljiška politika (agrarna in stavbna), praktično ne obravnava nekaterih zelo pomembnih soodvisnosti dejavnikov, ki »proizvajajo« mestni prostor; ni upoštevan javni interes napram zasebnemu, ni zadostnih specificiranih finančnih virov za ustvarjanje »banke stavbnih zemljišč«, ki bi omogočala skladnejše (in bolj sonaravno!) načrtovanje mesta za daljše časovno obdobje in s tem tudi smotrnejšo lokacijsko politiko in s tem tudi ni realnih možnosti za razmah neprofitne stanovanjske ter druge, socialno občutljive graditve;

- $\quad$ stanovanjska politika v povezavi s populacijsko in socialno politiko bi moralazagotavljati prednostno reševanje bivalnih pogojev mladih družin in deficitarnih strokovnih kadrov, učinkovito bi morala zaščititi najemnike stanovanj v zasebni lasti (in zlasti obsežni residuum najemnikov v denacionaliziranih stanovanjih), spoznati in obvladati bi morala vse fasete upravljanja s kondominiji (individualno lastništvo stanovanj v večstanovanjskih zgradbah), posebej zato, ker ima Slovenija nenormalno visok delež stanovanj v zasebni lasti, ki je posledica slabo premišljene prevratne zakonodaje;

- $\quad$ prometna politika, (če jo v resnici sploh imamo!) bi morala posebej obravnavati urejanje prometa $\mathrm{v}$ mestih in $\mathrm{v}$ obmestnem prostoru, kjer bi morala vzpodbujati uporabo javnega 
potniškega prometa in zavirati uporabo osebnih avtomobilov, vključno s policijskim podpiranjem restriktivnih ukrepov na tem področju; tudi za Slovenijo velja evropska krilatica $» 80 \%$ prometnih tokov na $20 \%$ cest $«$ in zaradi tega morajo biti avtoceste $\mathbf{v}$ vplivnem območju mesta, zlasti pa $v$ urbanistično-ureditvenem območju mesta, integrirane $v$ mestno cestno omrežje;

- varstvo in izboljševanje okolja $\mathbf{v}$ mestih sedaj nima ustrezne državne podpore $\mathrm{v}$ delovanju inšpekcijskih služb, v preprečevanju agrarne kemizacije v območjih zaščite virov pitne vode itd;

- izobraževanje, raziskovalno in razvojno delo morajo predstavljati poseben sklop zelo akcijsko usmerjenih politik, ki naj npr. spreminjajo Ljubljano, Maribor, Celje, Novo mesto, Koper, Novo Gorico in druga večja mesta v Mesta znanja.

Naštel sem le glavne problemske sklope, so pa še drugi, ki so »soodvisni« in so tudi neposredno odvisni od ustrezne skrbi države in/ali bodočih regionalnih skupnosti, npr. materialni pogoji visokega šolstva, raziskovalnega dela za industrijo in druge veje gospodarstva, zdravstva itd. Sem bi sodilo pospeševanje mestnega turizma, gospodarska promocija mesta, racionalnost upravnih postopkov itd., tedaj stvari, ki krepijo primerjalne prednosti naših mest v omrežju evropskih, zlasti bližnjih, mest. Naj kot zadnje, ki pa ni najmanj važno, omenim upravnopravno problematiko. Ta je seveda povezana s številnimi vidiki zemljiške politike in z že omenjeno konsolidacijo upravne in strokovne službe, ki se je razvila iz klasičnih mestnih gradbenih uradov (in zanje značilnega regulacijskega urbanizma), šla mimo mejnikov s konca 50-ih, oz. začetka 60-ih let, dalje mejnikov, ki so pomenili zanimivo vzpostavitev tripartitnih »kolektivnih organov odločanja « v obliki nekdanjih Komitejev ${ }^{15}$ in končno sedanjih oddelkov ali načelstev mestnih in občinskih uprav, ki imajo za strokovne partnerje zasebne projektantske organizacije. Izbrani problemski sklopi in poudarki nikakor ne pomenijo zanemarjanja ali celo nerazumevanja posebne ekonomske in socialne problematike manj razvitih regij. Izražajo le prepričanje, da so splošni pogoji za ustvarjanje presežne vrednosti v mestih (in somestjih) boljši in da pospešen razvoj mest pomeni tudi širšo osnovo za vlaganja v manj razvite regije. In končno: formalna in dejanska vzpostavitev regionalne (samo)uprave pomeni vzpostavitev logičnega okvira za usklajevanje vseh dejavnikov in vplivnikov »proizvodnje prostora«.

\section{PRED ZAKLJUČKOM PROGRAMA IZGRADNJE AVTOCEST IN O NEKATERIH DRUGIH VPRAŠANJIH PROSTORSKE INFRASTRUKTURE}

Uresničitev prvega dela velikega nacionalnega projekta, kar izgradnja osnovnega križa avtocest zagotovo je, se bliža zaključku. V prihodnjih 3 do 5 letih bomo na sklenjenih odsekih že lahko

\footnotetext{
${ }^{15} \mathrm{~V}$ Mestnem komiteju za urbanizem in varstvo okolja smo imeli v 70 -ih in 80-ih letih takle sestav: predstavniki delegatov Mestne skupščine, predstavniki strokovnih organizacij in predstavniki civilne družbe. Mimogrede: na seje so bili vedno vabljeni novinarji.
} 
preverjali predpostavke in zahteve varstva okolja, pričakovanega ali vplivanega regionalnega in urbanega razvoja in podobna vprašanja, ki so jih vsebovali načrti AC in recenzije le-teh. In še več, v približno istem času bomo lahko presojali komplementarne vplive modernizirane železnice in nekatere prostorske učinke članstva v Evropski uniji, med drugim tudi učinke schengenske meje na Muri, Sotli, Kolpi in predvsem med Slovensko in Hrvaško Istro, eminentnima turističnima subregijama, ki pravzaprav nikoli nista bili strogo razmejeni. Kot vse kaže, bomo lahko še veliko modrovali o povezanosti in o ločenosti urbanih centrov Istre, Primorja, Krasa, Furlanije in Julijske Benečije ter o zapletenosti depolitizacije Evroregije, v kateri se križajo slovanski, romanski in germanski interesi ...

Zadnja leta uresničevanja avtocestnega program zaznamuje nova finančna kriza, ki ima sicer veliko vzrokov vendar se jim bom v tem prispevku namenoma ognil. Omenil bom le en sklop problemov, ki neposredno zadeva funkcioniranje avtocest $\mathrm{v}$ vplivnih območjih mest ali v urbanih funkcionalnih regijah. Upravljalec avtocest, ki se postopno pretvarja v zasebno delniško družbo si ta hip prizadeva vzpostaviti zaprt cestninski sistem in gre pri svojih intencijah do absurdnih skrajnosti. Nekateri zastopniki DARSa so npr. izražali zahtevo po premaknitvi cestninske postaje Torovo (vsaj) na odsek med Šmartnim pod Šmarno goro in Vodicami ali celo na obroč mestne obvoznice. Zaradi maksimiranja cestnine naj bi s traso nove AC uničili hitro cesto H1, tj. »Cesto Bratstva in enotnosti« med Novim mestom in Trebnjem in še kaj. Take težnje pomenijo popolno nerazumevanje nastanka in krepitve novega modela »regionalnega mesta«, ki se, sicer v glavnem stihijsko, uveljavlja z novimi trendi v procesu suburbanizacije. Te nove trende bi lahko na kratko povzeli z nastanitvami premožnejših ljudi v obmestje, z nastajanjem »robnih mest« (Edge Cities), ki jih predstavljajo gigantska nakupovalna in storitvena središča ter s porastom uporabe osebnega avtomobila. Seveda gre pri vsem tem tudi za vpliv nove tehnologije oskrbe in pretoka informacij in morda tudi za močne premike $\mathrm{v}$ sistemih vrednot prebivalstva.

Zaradi pravilne tematizacije soodvisnosti širših in ožjih meril urejanja in oblikovanja prostora sem se v preteklih letih večkrat zavzemal zato, da bi projektiranje avtocestnih tras in njihova presoja potekalo vzporedno $\mathrm{z}$ revizijo obstoječih urbanističnih zasnov mest, ki jih nove avtoceste dejansko tangirajo. Koristnost tega zavzemanja se je pokazala najprej pri Kozini in Novem mestu, pozneje pa zlasti v Trebnjem, kjer je bilo prelitega preveč črnila v brezplodnih prepirih predno je bilo npr. ugotovljeno, da mesto zares potrebuje novo obvoznico in da je zanjo najprimernejša preureditev ceste H1. Kritičen pregled urbanistične strukture in ovrednotenje prostora pa je pomagalo najti tudi ustrezne lokacije za priključke mestnega in regionalnega sistema cest na avtocesto, da o potrebnih izboljšavah in o novi vlogi nekaterih regionalno pomembnih cest niti ne govorim.

Zanimivo je tudi dejstvo, da se kažejo v novi luči problemi navezave avtocestnega sistema sosednje države, Republike Hrvaške, na evropski sistem avtocest. Odgovorni dejavniki naše države očitno niso naklonjeni izgradnji manjkajočih členov AC med Trstom in Reko (in Istro) ter med Mariborom in Macljem, oz. Zagrebom. Hkrati pa so bile že naročene in se nadaljujejo študije za vzpostavitev »Tretje razvojne osi RS« tj. hitre ceste ali celo avtoceste med Koroško in Belo Krajino, oz. med avstrijskim sistemom AC v Labodski dolini in hrvaškim sistemom AC pri Karlovcu ali celo pri Bosiljevem (?), ki naj bi pomenila tudi zdaj zelo šibko gospodarsko interakcijo med koroškim, šaleškim, celjskim, zasavskim in posavskim somestjem, Novim 
mestom, ki ima menda najvišjo stopnjo gospodarske rasti ter Belo Krajino. Te razsežnosti, ki jih tu tako površno naštevam, so razsežnosti večje ali manjše kohezije slovenskih regij in subregij, so razsežnosti večje ali manjše socialne integracije in - koliko(?) večjih obremenitev okolja.

Sprva sem hotel v zaključnem delu tega prispevka zaokrožiti krajinsko in urbanističnooblikovalske vidike bodočnosti našega prostora. Mislim na tiste vidike, ki so v resnici pogoji humanega bivanjskega okolja. Pozneje sem pri sebi ugotovil, da gre za vidike, ki so sicer zelo pomemben kazalec soodvisnosti regionalnega in urbanističnega planiranja, odpirajo pa preveč resnih dilem, da bi jih bilo mogoče in prav celovito nakazati ali celo reševati na tem mestu. Eno zagotovo drži: planiranje, prostorsko širše ali prostorsko ožje, ne sme biti samo sebi namen. $Z$ drugimi besedami: regionalna izhodišča so potrebna za vsebinsko in po merilu ožje načrtovanje in obratno: »urbanistična merila« so lahko pomembni kriteriji za konkretizacijo ciljev regionalnih planov. Pač po tistem pravilu: od širšega k ožjem in od ožjega k širšem, od celot $\mathrm{k}$ podrobnostim in obratno. Človek je v temelje metodike svojega mišljenja in dela vgradil dedukcijski in indukcijski pristop k reševanju problemov. Na vrhu vsega pa imamo $\mathrm{v}$ kontekstu regionalnega razvoja opraviti še s posebnostmi regij, vključno posebnostmi v podobi pokrajine, oz. v krajini. Slovenija je v tem pogledu izjemna po raznovrstnosti krajin in seveda tudi po kulturnem izročilu in spomeniški dediščini. To je bil vedno velik izziv za naše oblikovalce. Ostanimo na koncu le pri ugotovitvi, da nam »dialog « med ravnemi med drugim omogoča izbiranje in postavitev končnih ciljev naših strokovnih prizadevanj. Metaforična raba pojma »dialog« pa naj na tem mestu pomeni tudi poziv k čimprejšnji opredelitvi regij in usposobitvi njihovih samouprav, seveda v sozvočju z ožje krajevnimi in širšimi, državnimi odgovornostmi.

\section{INTERDEPENDENCE OF REGIONAL AND URBAN PLANNING IN THE REGIONAL DEVELOPMENT OF SLOVENIA}

\section{Summary}

The article focuses on the significance of Slovene's concept of polycentric spatial development, and on the problems (more or less planned) of the transport infrastructure development, after the critical introduction of interdependence of regional and urban planning in general theory and Slovene's practice of regional and urban development. Within this context the emphasis is on the existing and future system of motorways and the greater role of public transport. Both aspects should be closely examined according to their environmental and spatial impacts and social integration (cohesion policy), and according to the landscape and urban design as the basic elements of human dwelling environment.

I believe that absence or disablement the state's participation in directing the urbanization processes is clearly visible from the following programming complexes:

- land use policy (agrarian and building) when used in practice, does not handle some of the most important interdependent factors, which enable the existence of the urban space; public interest is not considered against private, there are no sufficient specific financial 
resources to creating »bank of building lots« which would enable more accordant (and more sustainable) city planning for a longer period, as well as locational policy. Accordingly, there are no realistic possibilities for a full swing of the non-.profit housing and other socially sensitive buildings;

- housing policy related to the demographic and social policy should assure the following: prioritised solving of dwelling conditions for young families and deficiency of professional trained specialists; effectively protect tenants of flats in private properties (and especially residuum tenants in denationalised flats); recognize and master all the facets of management with condominums (individual property of flats in multi-dwelling buildings) apart, because Slovenia has no normal degree of flats in private hands, which is the result of poorly determined subversive legislation;

- transport policy (if we have it at all?) should separately considered regulation of transport in cities and suburban areas, where it should stimulate the use of public transport and restrict the use of private cars, including the stimulation of restrictive measures by the police. Namely, the European catchphrase $» 80 \%$ of traffic flow on $20 \%$ of roads « can justly be applied to Slovenia, which is why the motorways should be in influential areas of the cities, particularly in urban-designed areas of cities, integrated into the urban road system;

- $\quad$ protection and betterment of the environment in cities has in fact, no appropriate state support in supervision activities, or in preventing the agrarian chemization of protected areas of drinking water etc.;

- education, research and development activities should present special areas of actionorientated policies, which should change Ljubljana, Maribor, Celje, Novo mesto, Koper, Nova Gorica and other larger cities into Cities of knowledge. 